\title{
Nutmeg Intoxication Associated with Consumption as a Stupefacient
}

\author{
Mücahit Günaydın', Özgür Tatlı², Gürkan Altuntaş3 , Zakire Uslu4, Faruk Özşahin', Necla Beşlioğlu \\ 'Department of Emergency Medicine, Giresun University School of Medicine, Giresun, Turkey \\ ¿Department of Emergency Medicine, Karadeniz Technical University School of Medicine, Trabzon, Turkey \\ Department of Emergency Medicine, Rize Training and Research Hospital, Rize, Turkey \\ ${ }^{4}$ Department of Emergency Medicine, Kanuni Training and Research Hospital, Trabzon, Turkey \\ 5Department of Emergency Medicine, Giresun Professor Doctor Illhan Özdemir State Hospital, Giresun, Turkey \\ ${ }^{6}$ Department of Emergency Medicine, Gümüşhane State Hospital, Gümüşhane, Turkey
}

Cite this article as: Günaydın M, Tatlı Ö, Altuntaş G, Uslu Z, Özşahin F, Beşlioğlu N. Nutmeg Intoxication Associated with Consumption as a Stupefacient. J Emerg Med Case Rep 2017; 8: 64-5.

\begin{abstract}
Introduction: Nutmeg is the dried seed of an evergreen aromatic tree from the plant family Myristicaceae. It is widely used in traditional medicine. Although misuse is rare, it needs to be understood that this plant, widely used as a spice in various parts of the world, can be misused and can result in emergency presentation due to intoxication.

Case Report: We describe a case of intoxication in a 22-year-old male student after he mixed nutmeg with fruit juice and drank it. Neurological symptoms and anticholinergic signs were present during presentation.

Conclusion: Nutmeg intoxication must be one of the possibilities considered at differential diagnosis in patients presenting to the emergency department with findings of anticholinergic intoxication.
\end{abstract}

Keywords: Nutmeg, mydriasis, poisoning

Received: 30.09.2016 Accepted: 01.11.2016 Available Online Date: 15.02.2017

\section{Introduction}

Nutmeg is the dried seed of an evergreen aromatic tree from the plant family Myristicaceae. It is widely used as a traditional treatment for fever, the common cold, respiratory diseases, and mange and as an appetite enhancer and an antiemetic and to induce miscarriage and reduce gas (1). Nutmeg is widely used domestically as a flavoring and spice agent. However, it is also known to be used recreationally because of its hallucinogenic effects (2). Because cases of recreational misuse and associated intoxication are uncommon, it may be difficult to diagnose such cases in the emergency department.

\section{Case Report}

A 22-year-old male university student was brought to the emergency department because of an altered state of consciousness and hallucinations. We learned that the patient had crushed six cloves of nutmeg and mixed these with fruit juice and drunk this approximately $8 \mathrm{~h}$ before admitting to emergency service. Nausea, dry mouth, and facial flushing commenced approximately 6 $\mathrm{h}$ after consumption, followed by an altered state of consciousness. He had no history of smoking and alcohol or drug use or disease. Blood pressure at the time of presentation was 140/90 mmHg, heart rate 75 beats/min, respiratory rate 20 breaths/min, body temperature $36.5^{\circ} \mathrm{C}$, and oxygen saturation at room temperature $98 \%$. At initial examination, the Glasgow Coma Score was 13, orientation and cooperation were limited, and agitation and incoherent speech were observed. Both pupils were mydriatic, and light

This study was presented at the $4^{\text {th }}$ Eurasian Congress of Emergency Medicine, 12-16 November 2014, Belek, Antalya.

Address for Correspondence:

Mücahit Günaydın, Department of Emergency Medicine, Giresun University School of Medicine, Giresun, Turkey

E-mail:mgunaydin@hotmail.com

oCopyright 2017 by Emergency Physicians Association of Turkey - Available online at www.jemcr.org 
reflex was bilateral positive. Other system examination findings were normal. Electrocardiogram was in a normal sinus rhythm. Complete blood count, kidney and liver function tests, serum electrolytes, arterial blood gas values, and cardiac markers were normal. The patient was admitted to the intensive care unit with a diagnosis of nutmeg intoxication. Symptomatic treatment and intravenous fluid therapy were started. Intravenous midazolam was administered for sedation. Consciousness returned to normal status after $12^{\text {th }}$ hour of nutmeg intake and all symptoms resolved entirely. Vital signs were stable throughout hospitalization, and no impairment was observed in laboratory values. The patient was discharged following a 48-h follow-up.

\section{Discussion}

In addition to being consumed as a spice, nutmeg is also used for recreational purposes because of its euphoric and hallucinogenic effects. Misuse has been reported among adolescents, students, and prisoners who experience a difficulty in obtaining other stimulants $(3,4)$. Nutmeg is sold in clove or powder form and is generally consumed as a powder. One clove of nutmeg is approximetely 7 grams but 5 to 30 grams is needed for abuse (2-4).

Nutmeg oil contains the compounds myristicin, elemicin, safrole, methyl eugenol, eugenol, methyl isoeugenol, methoxy eugenol, isoeugenol, isoelemicin, and toluene. Myristicin and elemicin are thought to be responsible for the pharmacological effects of nutmeg. Both myristicin and elemicin possess anticholinergic and psychotropic properties (2). Myristicin has been shown to possess structural similarities to classic hallucinogenic compounds such as mescaline, and it is therefore thought to be capable of acting as a serotonin receptor agonist and hallucinogenic agent. Although myristicin constitutes a large part (approximately 4\%-8\%) of the compounds in the aromatic fraction of nutmeg, the number of human studies involving myristicin and investigating the effects of nutmeg intoxication on the central nervous system is low. Myristicin and elemicin impair coordination and reduce motor activity in rodent studies. No similar behavioral effects have been determined in safrole, eugenol, and isoeugenol in these animal studies (4). The hypolipidemic and cholesterol-lowering effects of the chemical compounds of nutmeg have been investigated by researchers in various scientific disciplines for their antimicrobial, antidepressant, aphrodisiac, memoryenhancing, antioxidant, and hepatoprotective properties (5).

Similarly to belladonna alkaloid or atropine intoxication, the clinical characteristics of nutmeg intoxication include flushing of the face, tachycardia, hypertension, dry mouth, blurred vision, agitation, and delirium. Symptoms begin approximately 3-6 h after ingestion and generally resolve in 24-36 h. Tachycardia may frequently be observed as the only finding. Hypotension and shock are rare. Chronic psychosis has been reported with long-term use. However, in contrast to other anticholinergic intoxications, it frequently leads to miosis, while mydriasis is rare, although there is no definite evidence on this subject $(4,6,7)$. One study investigating pupillary responses observed miosis for $13 \mathrm{~h}$ after ingestion in some cases and mydriasis for $5 \mathrm{~h}$. Cat studies have failed to elicit local mydriatic action. Pupillary findings are not therefore reliable in the diagnosis of nutmeg intoxication (7). Mydriasis was present in our case. The altered state of consciousness and delirium reported in previous cases were also observed in our patient, but contrary to the information in the literature, there was no taschycardia or hypertension.

The information in the literature concerning the management of nutmeg intoxication is insufficient. Most patients recover without sequelae, although a case of nutmeg intoxication-related death has also been reported (6). Patient management generally involves support therapy. Standard antiemetic (prochlorperazine, trimethobenzamide, ondansetron and metoclopramide) and intravenous fluid use can be used to treat prolonged nausea and vomiting (4). Sedation with benzodiazepines can be used to calm the patient and to reverse amphetamine-like effects. Active charcoal can help reduce absorption, while inducing vomiting is controversial (7).

\section{Conclusion}

In addition to being intensively used in various regions of the world, nutmeg is also widely sold as a spice in Turkey. It is much more easily available for misuse than other stimulants. No cases of acute nutmeg intoxication have previously been reported from Turkey. Nutmeg use is widespread, and a larger number of cases of intoxication may be anticipated. It is important for these cases not to be confused with other diagnoses in the emergency department.

Because of could not be reached to patient after treatment, informed consent could not be taken.

Informed Consent: Written informed consent couldn't be obtained due to the impossibility of reaching the patient.

Peer-review: Externally peer-reviewed.

Author contributions: Concept - M.G.; Design - Ö.T.; Supervision - Z.U.; Resource - G.A.; Materials - N.B.; Data Collection and/or Processing - Ö.T.; Analysis and/or Interpretation - F.O.; Literature Search - G.A.; Writing - M.G.; Critical Reviews - M.G.

Conflict of Interest: No conflict of interest was declared by the authors.

Financial Disclosure: The authors declared that this study has received no financial support.

\section{References}

1. Hayfaa AA, Sahar AM, Awatif MA. Evaluation of analgesic activity and toxicity of alkaloids in Myristica fragrans seeds in mice. J Pain Res 2013; 6: 611-5. [CrossRef]

2. McKenna A, Nordt SP, Ryan J. Acute nutmeg poisoning. Eur J Emerg Med 2004; 11: 240-1. [CrossRef]

3. Quin Gl, Fanning NF, Plunkett PK. Nutmeg intoxication. J Accid Emerg Med 1998; 15: 287-8. [CrossRef]

4. Barceloux DG. Nutmeg (Myristica fragrans Houtt.). Dis Mon 2009; 55: 373-9. [CrossRef]

5. Shafiei Z, Shuhairi NN, Md FazlyShah Yap N, Harry Sibungkil CA, Latip J. Antibacterial activity of myristica fragrans against oral pathogens. Evid Based Complement Alternat Med 2012; 2012: 825362. [CrossRef]

6. Stein U, Greyer H, Hentschel H. Nutmeg (myristicin) poisoning--report on a fatal case and a series cases of recorded by a poison information centre. Forensic Sci Int 2001; 118: 87-90. [CrossRef]

7. Demetriades AK, Wallman PD, McGuiness A, Gavalas MC. Low cost, high risk: accidental nutmeg intoxication. Emerg Med J 2005; 22: 223-5. [CrossRef] 